\title{
Urban bat pups take after their mothers and are bolder and faster learners than rural pups
}

\author{
Lee Harten ${ }^{1}$, Nesim Gonceer ${ }^{1}$, Michal Handel', Orit Dash', H. Bobby Fokidis ${ }^{2}$ and Yossi Yovel ${ }^{1,3,4^{*}}$ (D)
}

\begin{abstract}
Background: Urbanization is rapidly changing our planet and animals that live in urban environments must quickly adjust their behavior. One of the most prevalent behavioral characteristics of urban dwelling animals is an increased level of risk-taking. Here, we aimed to reveal how urban fruitbats become risk-takers, and how they differ behaviorally from rural bats, studying both genetic and non-genetic factors that might play a role in the process. We assessed the personality of newborn pups from both rural and urban colonies before they acquired experience outdoors, examining risk-taking, exploration, and learning rates.

Results: Urban pups exhibited significantly higher risk-taking levels, they were faster learners, but less exploratory than their rural counterparts. A cross-fostering experiment revealed that pups were more similar to their adoptive mothers, thus suggesting a non-genetic mechanism and pointing towards a maternal effect. We moreover found that lactating urban mothers have higher cortisol levels in their milk, which could potentially explain the transmission of some personality traits from mother to pup.
\end{abstract}

Conclusions: Young bats seem to acquire environment suitable traits via post-birth non-genetic maternal effects. We offer a potential mechanism for how urban pups can acquire urban-suitable behavioral traits through hormonal transfer from their mothers.

Keywords: Personality, Urbanization, Maternal effects, Risk-taking

\section{Background}

The existence of consistent intra-species, inter-individual differences in behavior, often referred to as personality traits $[1,2]$, is now well established in a wide range of animal taxa [1-12]. The notion that this behavioral variation is merely a result of statistical "noise", is progressively changing to the understanding that such variability may be in itself adaptive and thus maintained by natural selection $[2,6$, 13-20]. One interesting idea is that intra-species behavioral variation is adaptive because of the heterogeneity and

\footnotetext{
* Correspondence: yossiyovel@gmail.com

${ }^{1}$ School of Zoology, Faculty of Life Sciences, Tel Aviv University, 69978 Tel Aviv, Israel

${ }^{3}$ Sagol School of Neuroscience, Tel Aviv University, 69978 Tel Aviv, Israel Full list of author information is available at the end of the article
}

dynamics of available living habitats [21-23]. Indeed, evidence suggests that behavioral traits in various groups such as insects, reptiles, birds, and mammals diverge along environmental gradients [21, 24-30]. Behavioral gradients can be a result of exposure to local stimuli, learning, environment-specific selection pressures, or individual differences in perception (e.g., threats). Increasing evidence indicates that an animal's personality shapes how it exploits novel environments. The rapid increase in urbanization [31] is an especially good example where behavioral variability can be advantageous. Exploiting an urban environment often requires a specific set of skills, due to the distinctly different challenges, risks, and rewards presented by urban environments in comparison to the natural habitats where animal behavior has evolved [26, 28]. Indeed, 
one of the phenomena found repeatedly is that bolder individuals with a greater propensity to take risks colonize urbanized habitats more rapidly than shyer, less bold, and often also less aggressive individuals [2, 21, 32-36].

A major open question is how such urban-related behavioral traits are acquired. It remains unknown if they are a result of selection, of non-genetic inheritance, of self-experience and learning, or of a combination of the above, as different studies suggest [21, 24, 37-39]. Some studies examining the genetic basis of personality found that up to $30 \%$ of individual differences in behavior are genetically inherited $[14,29,40]$. Dingemanse et al. (2002) for example reported that $30 \%$ of the variation in explorative behavior of great tits was attributed to their wild-caught parents [41]. Similarly, Alpine swifts resembled their genetic, but not foster parents in their antipredator behavior [42]. Alternatively, a divergence of personality traits across environmental gradients might suggest non-genetic processes such as parental programming or individual experience-based learning [7, 29, 43, 44]. Maternal effects have been shown to influence the development of offspring behavioral traits in various ways [44-47]. Maternal effects include nutrient provisioning, hormone transfer, social interactions, or serving as a model to learn from $[44,48,49]$. For example, individual differences in maternal care and in stress reactivity are behaviorally transmitted between generations in rats [45], and the exploratory tendencies of young zebra finches are better predicted by the exploratory behavior of the foster than the genetic parents [29].

The Egyptian fruitbat, Rousettus aegyptiacus, successfully exploits human-altered landscapes and can be found abundantly both in urban and in rural environments in Israel. In a preliminary study, we revealed significant differences in the risk-taking behavior of fruitbats from rural and urban colonies with urban bats being bolder risktakers (Additional file 1: Figure S1). Furthermore, these bats exhibit relatively long offspring dependency (up to 4 months), increasing the potential for different types of maternal influences on pup behavior. Taken together, this species presents a unique opportunity to detangle the determinants of personality traits across environmental gradients. We used common garden experiments, which remove the confounding effects of the rearing environment, in combination with cross-fostering experiments, to explore divergence in behavioral traits between urban and rural newborn pups and to explore whether these differences are innate or acquired.

\section{Results}

\section{Urban and rural pups consistently differ in behavioral} traits

In total, we carried out behavioral assays on 86 bat pups with no self-experience outdoors, across three years including 61 pups from four urban colonies and 25 from three rural colonies (Methods, Additional file 1: Table S1). We used the foraging box assay to assess bat personality (Methods). This assay has been successfully utilized by us in a preliminary study, showing behavioral differences between urban and rural adult fruitbats (Additional file 1: Figure S1). The setup consists of six identical plastic boxes placed on the floor, each with ample available fruit inside. A single bat at a time was allowed to explore the room for an entire night and it had to enter the boxes in order to eat.

Pups originating from urban and rural colonies differed consistently and significantly in risk-taking, exploratory, and learning behaviors:

1) Risk-taking was defined as the proportion of times an individual entered boxes after landing on them. Fruitbats typically show high vigilance when landing and hesitate before entering a box positioned on the ground as we have shown in the previous [50]. This hesitance is also typical for these bats when landing on low tree branches in the field [50].

2) Exploration was defined as the proportion of unique boxes entered by an individual throughout the experiment (the unique number of visited boxes divided by the total number of boxes). As all boxes contained ample food, in theory, a bat could have continued exploiting the first box it entered all night.

Note that risk-taking and exploration are not necessarily linked. An individual could land on six different boxes and enter them all, and thus be ranked an exploratory risk taker; it could land on a single box ten times and enter it once, thus ranked non-exploratory and hesitant, and it could show any combination of the two traits.

3) Learning: To test learning, we slightly changed the setup, now allowing access to the food only in one of the boxes, so that a bat that already experienced the previous setup had to learn that only one box offers food. We then measured the average error rate, i.e., the number of times a bat sampled wrong boxes, after discovering they are no longer rewarding, divided by its general activity (i.e., the sum of all landings).

Urban-born pups exhibited greater risk-taking and faster learning than rural pups (Fig. 1A, C; Risk-taking: 0.62 \pm 0.16 vs. $0.41 \pm 0.14$ box entries per landings, respectively, $R^{2}=0.58 P<0.0001$, mixed model GLM with risktaking set as the response variable, the origin and fostering condition (i.e., biological, or foster mother) as fixed 


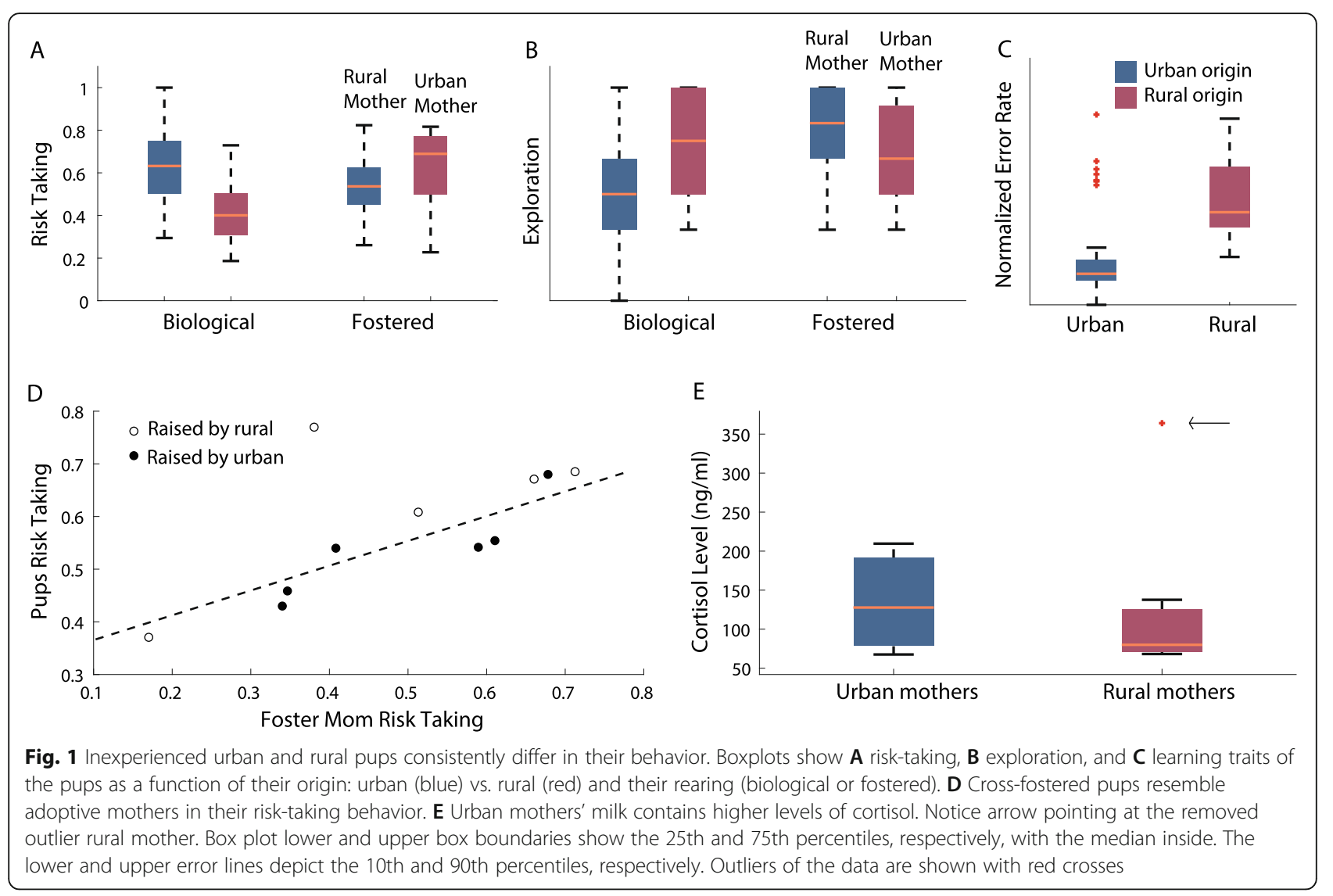

factors; and the bat's ID and the year of the experiment as random effects, $n=86$ bats). Results remained highly significant when excluding the cross-fostered bats $(n=$ $11)$, which were only tested in year $3(P<0.00001$; learning: $0.19 \pm 17$ vs. $0.45 \pm 0.19$ error rates, respectively, $R^{2}=$ $0.72, p<0.00001$, mixed GLM with learning set as the response variable, the origin as a fixed factor and the bat's ID as a random effect, $n=65$ ). Both traits (risk-taking and exploration) were repeatable across trials $(R$ values for Pearson's correlation varied between 0.55 and 0.66 for risk-taking, Additional file 1: Figure S2A, $p<$ 0.02 and between 0.6 and 0.86 for exploration, $n=48$ individuals, Additional file 1: Figure S2B, $p<0.004$ ). Urban pups were also less exploratory than rural pups (Fig. 1B; proportion of visited boxes $-0.73 \pm 0.22$ vs. $0.58 \pm 0.23$, for rural and urban pups respectively, $R^{2}=0.59, p=0.001$, mixed model GLM as above, but with exploration set as the response variable).

The differences in both risk-taking and exploration were observed two years in a row, even when examining the data of each year separately $(P<0.0001$ and $P=0.0003$ for risk-taking and $P=0.009$ and $P=0.03$ for exploration, mixed effect GLM as above, without the year random effect). As pups never experienced their environment of origin independently, we can rule out that these differences are a result of environment experiential effects.
Some of the traits were correlated with each other. Risk-taking was negatively significantly correlated with the error rates in the learning task and nearly significantly correlated with exploration, that is, pups more prone to take risks exhibited faster learning and less exploration $(R=-0.47, P=0.0001 ; R=-0.19, P=0.07$; respectively, Pearson's correlation test). The negative correlation between the error rates in the learning task and exploration also approached significance (Pearson's correlation test; $R=-0.22, P=0.08$; respectively). Neither sex nor age at first experimental exposure, influenced the pups' risk-taking, exploratory behavior, or learning (sex: $P=0.37$, age: $P=0.12$; sex: $P=0.07$, age: $P=$ 0.8 ; sex: $P=0.9$, age: $P=0.23$; respectively; mixed model GLM, as above but with sexlage added as fixed factor.)

\section{Pups are more similar to their adoptive than to their biological mothers}

To examine whether the behavioral differences between urban and rural pups are innate or acquired post-birth through maternal effects, we carried out cross-fostering experiments, where we attached pups from urban colonies to mothers from rural colonies who reared them and vice-versa ( $n=11$ mother-pup pairs). The crossfostering was performed during the first 3 weeks of the pups' lives in which they are constantly attached to their 
mothers' nipple. Pups remained with either their biological or adoptive mothers' care for another ca. 80 days prior to participating in the behavioral assays, thus providing the opportunity for maternal effects to take place.

Cross-fostering significantly affected pups' risk-taking behavior, suggesting a maternal role in the acquisition of this behavioral trait. Rural pups raised by urban mothers were more prone to take risks than rural pups raised by rural mothers (Fig. 1A, cross-fostering had a significant effect on risk-taking, $P=0.003$ for the effect of the fostering condition, mixed effect GLM with risk-taking set as the response variable, the origin and rearing conditions as fixed factors, and the bat's ID and year of experiment set as random factors, $n=86$ bats, 156 trials). Post hoc contrasts showed that fostered rural bats exhibited significantly higher risk-taking than biologically raised rural pups, whereas the difference between fostered and biologically raised urban pups only approached significance $(P<0.0001$ and $P=0.056$; respectively, the critical $p$ value following a Bonferroni correction was 0.025$)$. Furthermore, we found that cross-fostered pups resembled their adoptive mother and not their biological mothers in their levels of risk-taking. Pups' risk-taking was significantly positively correlated with that of their adoptive mothers, (Fig. 1D $R=0.65, p=0.02$, Pearson's correlation; $n=11$ pairs). Pups' risktaking was negatively (non-significantly) correlated with that of their biological mothers $(R=-0.59 . p=0.07$, Pearson's correlation; $n=7$ pairs).

Although fostering showed the same patterns for exploration (Fig. 1B), the effect was only significant for the interaction between the origin of the pups and the fostering condition suggesting that pups from rural colonies changed significantly more under cross-fostering. $(P=$ 0.07 for the fostering condition and $p=0.04$ for the interaction between the origin and the rearing condition, mixed model GLM as above but with exploration as the response variable). In the case of the exploration, there was no correlation between the pups and either the biological or the foster mothers $(R=0.22, P=0.5 ; R=0.05, P=$ 0.9; Pearson correlation test, respectively).

Finally, to examine the possibility of a hormonal maternal influence on pup behavior, we examined cortisol levels in the milk of 31 lactating mothers (17 urban and 14 rural, see the "Methods" section). Urban bats had higher levels; significantly higher when removing one extremely rural outlier that was more than 2 standard deviations from the mean $(132 \pm 56$ vs. $92 \pm 26$ cortisol (ng/ $\mathrm{ml}$ ), for urban and rural mothers respectively; Fig. 1E, $P=0.4$ without removal and $P<0.02$ with the removal of one point, $T$ test).

\section{Discussion}

We set out to examine the determinants of the personality differences between adult Egyptian fruitbats from urban and rural colonies (Figure S1). We tested newborn pups in a common garden experiment, which eliminates confounding effects of self-experience and in a crossfostering experiment aiming to disentangle the contribution of genetic and maternal effects on offspring personality traits.

Bat pups originating from urban and rural environments significantly and consistently differed in their risk-taking, exploratory, and learning even though they were caught prior to developing flight abilities, and thus had no opportunity to independently experience the environment. In line with previous studies on a wide range of species (e.g. 1-6) urban bat pups exhibited significantly higher risk-taking tendencies than their rural counterparts.

Previous findings indicate that the roosting environment (urban or rural) of Egyptian fruitbats does not necessarily determine their foraging grounds of its inhabitants. However, although rural-dwelling Egyptian fruitbats spent on average $45 \%$ of their time foraging in settlements very few cases of urban-dwelling bats were observed consistently foraging in the countryside. Thus, the foraging and roosting ecology of urban and rural dwelling populations remain substantially different. Moreover, bats that roost in urban environments are more exposed to urban challenges than bats that roost in rural environments spend a few hours foraging in cities [51]. Indeed behavioral differences between urban and rural populations have been established both in the wild and captivity for this species (Additional file 1: Figure S1, [51]). The propensity of risk-taking is probably greater in urban dwellers because of their need to better cope with the novel challenges associated with the urban environment [2, 21, 32, 33]. Urban pups were also significantly faster learners than rural pups, supporting previous evidence that bolder (i.e., risk-taking) individuals learn faster (e.g. voles-12, 13). The ability to learn fast is thought to be especially advantageous in urban environments where environmental changes often outpace an animal's ability to adapt [52]. Urban risk-taking pups were significantly less exploratory than rural pups. This result is seemingly not in line with previous studies where proactive bold, risk-takers are typically also more exploratory $[5,10]$. However, exploratory tendencies are mostly measured in terms of speed of exploration, while here we measured whether individuals keep exploring after discovering a profitable resource. Our results thus might be similar to the findings that bold individuals also tend to be more rigid and routine-bound than shy counterparts, which might have led, in our case, to visiting the same boxes again and again and thus to being less exploratory according to our measurement [53].

After establishing that personality differences between urban and rural pups were not a result of environmental 
experience, we next used a cross-fostering paradigm to explore whether these differences were innate or acquired. We found that cross-fostering significantly influenced pups' risk-taking and exploration, suggesting a maternal role in the acquisition of these behavioral traits. Rural pups raised by urban mothers exhibited higher risk-taking and lower exploratory tendencies than rural pups raised by their biological mothers and urban pups raised by rural mothers exhibited reduced risktaking levels and more exploratory behavior. Furthermore, cross-fostered pups resembled their adoptive mothers and not their biological mothers in their risktaking tendencies, further strengthening the maternal role in the acquisition of this behavioral trait. We thus suggest that the difference in risk-taking and to a lesser extent exploration between urban and rural populations is due to post-birth non-genetic maternal effects. Moreover, the significant correlation between the risk-taking levels of the adoptive mothers and the adopted pups suggests that risk-taking was influenced by some maternal effect and not by the cross-fostering manipulation itself or by social learning from conspecifics. Although we cannot completely rule out the potential role of conspecifics, the chances to learn from a pup that was nonvolant for a substantial part of the period is low. This correlation also points against in-utero effects. Fostering mothers could influence pups through various mechanisms including social learning, hormone transfer, and other epi-genetic mechanisms. We find the social learning hypothesis less likely as pups did not have many opportunities to learn. In the relatively small colonies where the pups were held, mothers mostly perch near other bats or go down to the bowl of fruit to collect fruit. Of course, we cannot exclude the possibility that risk-taking mothers exhibit different behavioral patterns when performing these behaviors and that pups absorb and learn them. We find the hormonal hypothesis more likely and indeed our cortisol analysis suggests higher levels in urban bats, although more data is necessary to relate these levels with behavior. Hormonal levels, controlled via breast-feeding or elevated through maternal behavior have been shown to exert effects on offspring behavior in various species [44-46, 54-56].

Maternal cortisol-transfer can potentially have a profound impact on development; unfortunately, however, this area is understudied. The extremely high circulating cortisol levels reported for bat species [57-59] suggest that they would easily permeate all tissues. Thus, there is a good chance that even occasional urban-associated stressors may be sufficient to induce long-lasting changes in behavior. Furthermore, evidence from cows indicates that increased cortisol exposure is associated with increased permeability through the blood-milk barrier [60]; thus, there could be a positive feedback with cortisol dosing for the nursing young. The differences in cortisol levels we observe between the two populations might stem from various reasons unrelated to the ontogeny of pup behavior. For example, they might be related to metabolism. Cortisol is an energy mobilizing hormone firstly, and differences in metabolism could lead to such cortisol differences. Egyptian fruitbats have been shown to consume a greater variety of food sources per hour in urban environments. This may require increased cortisol levels in urban populations which in turn, might affect pup behavior. Interestingly, for both risk-taking and exploration, rural pups were more influenced than urban pups by the fostering manipulation. This suggests that if cortisol is the transmission mechanism, its presence during development affects behavior, but its relative absence has less effect. This is consistent with previous studies on how excessive concentrations of steroids cause changes in behavior. Our results are in line with several previous findings showing maternal effects on offspring personality [44]. For example, exploratory tendencies of young zebra finches are better predicted by the exploratory behavior of their foster parent rather than by their genetic parents [29]. Clearly, we cannot exclude some contribution of genetic predispositions to the behavioral traits that we studied. Indeed, conflicting results in the literature regarding the innate or acquired nature of behavioral traits (e.g., 17 vs. 47), indicate that inheriting and acquiring individual-specific behavioral traits are not mutually exclusive. The mechanisms shaping pups' behavior might depend on systemspecific selection pressures promoting flexibility and variation of different traits within populations. An interesting idea in this respect is the distinction between selection pressures exerted on flying vs. terrestrial animals; where terrestrial animals are expected to be subjected to stronger selection pressures given their reduced capability to vacate urban habitats resulting in reduced gene flow $[27,61-63]$.

\section{Conclusions}

In our rapidly changing world, it is crucial to understand what determines the success of certain individuals in urban environments. Specifically, are offspring of urban dwellers born adapted to urban environments? Our results join a substantial body of work exploring the influence of environmental [21,24-30], genetic [14, 29, 40], and maternal effects $[7,29,43,44]$, on behavioral traits of offspring. But, rarely has the effect of urbanization on behavioral traits been examined while controlling for both the rearing environment [27] and maternal effects, and to our knowledge, never has cross-fostering been attempted in bats before. We highlight the importance of maternal effects as a mechanism generating and maintaining behavioral variation in heterogeneous 
habitats. We offer a potential mechanism explaining how urban pups can acquire urban-suitable behavioral traits through hormonal transfer from their mothers.

\section{Methods}

Study site, study species, and colonies

Permits

All experiments were approved by the TAU IACUC permit number: 04-18-030. Bat capture was approved by the Israel National Park Authority.

\section{Captive colonies and experimental rooms}

Between September 2017-Jan 2018, April-May 2018, and April-May 2019, 86 Egyptian fruitbat pups were captured together with their mothers in natural rural and urban colonies and brought to the Zoological Garden at Tel Aviv University. Rural colonies consisted of natural caves outside settlements while urban colonies consisted of either caves or abandoned old buildings in the middle of the city (Additional file 1: Table S1). Rural colonies are positioned at least $10 \mathrm{~km}$ away from any city. Notably, roosting inside a city means much more interaction with humans and urbanization. To ensure that pups did not have any previous own navigational or foraging experience in their environment of origin we caught pups before reaching their volant stage, i.e., before reaching an age of 65 days or a forearm of $\sim 74 \mathrm{~mm}$ [64]. We further validated for each of the captured pups that it cannot fly independently before releasing in its respective colonies. All ages were approximated based on their forearm, using an equation fitted to empirical data of 38, pups born in the lab between 2012 and 2019 [64].

Year 1-2017 Thirty five mother-pup pairs were captured at a single urban colony and brought to the lab prior to developing independent flight (average pup age was $51 \pm 27$ days, 23 females, 12 males, Additional file 1 : Table S1).

Year 2-2018 Thirty mother-pup pairs were captured at 2 rural and 4 urban colonies (Additional file 1: Table S1, $n=15$ urban; average age at arrival $=37$ days, $n=15$ rural; average age at arrival $=40$ days, overall, 19 males, 11 females).

Year 3-2019 Twenty-one mother-pup pairs were captured at 2 rural colonies and 1 urban colony $(n=11$ urban; average age at arrival $=19$ days, $n=10$ rural; average age at arrival $=12$ days). To further exclude any effect of individual experience (even when carried by their mothers), in this season, we either caught pregnant mothers (who gave birth in the lab) or mothers with very young pups-the average forearm length was $48.7 \pm 10.0$ $\mathrm{mm}$ accounting for an age of 14 days on average.
Egyptian fruitbat pups are born with closed eyes and folded ears until they reach approximately 10 days of age [65], meaning that their sensory systems were at their most underdeveloped stage limiting experiences of their environment prior to arriving at the lab.

In both years 2 and 3, city and rural bats were housed separately in identical rooms $\left(\sim 2.5 \times 2 \times 2.5 \mathrm{~m}^{3}\right)$ with a (12:12) fluctuating day/night light cycle and a regulated temperature of $27^{\circ} \mathrm{C}$. Across all years, bats were weighed and scaled weekly to keep track of their growth and health. The fur of all individuals was bleached with unique identification marks, and an experimenter checked twice a day that all mother/pup pairs were together. Bats were provided with fresh fruit ad-lib daily, including watermelon, banana, apple, and melon.

\section{The foraging box-test}

Behavioral assays were conducted in order to assess individual personality traits. The experimental apparatus consisted of a tent $\left(3.9 \times 2.7 \times 1.9 \mathrm{~m}^{3}\right)$ placed inside a room, with six, identical plastic boxes placed on its floor (i.e., foraging boxes, $64 \times 38 \times 40 \mathrm{~cm}^{3}$ ). Each box had an entry hole $(10 \mathrm{~cm}$ diameter $)$ with a mesh ladder leading to a food source consisting of daily fresh seasonal fruit (i.e., banana, apple, watermelon, and melon with mango juice, Fig. 2). Boxes containing fruit were washed between trials. We used two identical experimental tents (positioned in different rooms) to nightly test two juvenile bats (one rural and one urban) simultaneously. Bats were tested individually overnight (for $12 \mathrm{~h}$ between 16:00 and 04:00) and they were removed from the room on the next morning. The experiments were recorded using an infrared video camera (Sony HDRCX730, Sony FDR-AX53), using an infrared light situated outside the

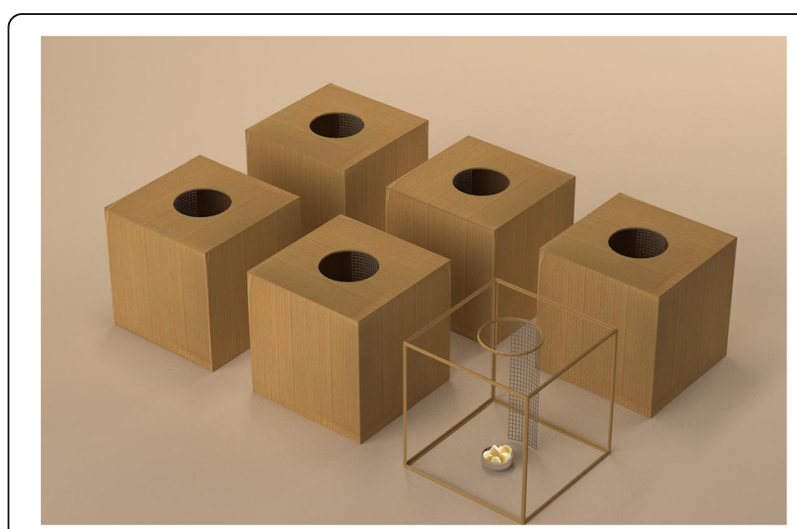

Fig. 2 The foraging box-test setup. Each box had a hole with a ladder leading inside to a bowl with 25 pieces of fruit $(150 \mathrm{~g})+$ nectar $(50 \mathrm{ml})$. During the basic setup sessions, all six boxes contained an accessible food bowl. The learning sessions were set up identically, but with only one box containing an accessible food source and the remaining boxes containing a food source covered with mesh (thus generating similar odor cues but inaccessible) 
tent to light the room homogeneously (Methaphase Technologies Inc-ISO-14-IR-24).

\section{Experimental procedure}

Experiments were carried out across the three years. At the beginning of each experimental batch, groups of five urban/ rural pups were separately exposed to the foraging box-test for one night. In this exposure night, each box contained $750 \mathrm{~g}$ of accessible fruit, enough to meet the nightly nutritional requirements of all participating bats together. The aim of this exposure was to let the juvenile bats explore the foraging boxes and learn to feed from them, and thus to exclude effects of neophobia in the latter experiments.

The basic setup Following the exposure session, each pup participated individually in between 1 and 3 sequential full-night sessions across consecutive nights (Additional file 1: Table S1. In the basic setup, each of the 6 boxes was accessible via a ladder, containing the same amount of excess food. Each box had 25 pieces of fruit $+50 \mathrm{ml}$ nectar, which amounts to $\sim 150 \mathrm{~g}$ and is enough food for a single bat per night to avoid any effects of food depletion. We used this paradigm to assess risktaking and exploratory tendencies (see below).

The learning setup This paradigm, used the same 6 box setup as above, only that now five out of the six boxes contained a non-accessible, food source, covered with mesh, providing similar olfactory cues but not allowing bats to reach the fruit. We tested the pups' ability to learn the changing conditions-they had to reverse their previous learning that all boxes offer available food.

In all experiments, at the beginning of the session, the pup was placed for approximately $30 \mathrm{~min}$ in a familiar carrying bag $\left(42 \times 26 \times 35 \mathrm{~cm}^{3}\right)$ to acclimate. The bag with the bat was then placed at the circumference of the tent with its opening facing the foraging boxes. The pup could exit the bag voluntarily. The order of pups used in the experiments was determined by age, with older pups tested first, to minimize age differences between the pups during the experiments. Urban and rural pups of the closest age were tested at the same time as much as possible. Pups on average were $91.3 \pm 38.5$ days old when participating in their first exposure experiment.

Cross-fostering experiments To examine whether the differences in personality traits between urban and rural pups were acquired or innate, in the third year, we performed cross-fostering experiments.

We cross-fostered 11 mother-pup pairs (6 rural and 5 urban, Additional file 1: Table S1). Each cross-fostered pup was detached from its biological mother and transferred to the nipple of a mother originating from a different environment of origin (i.e., urban pups were transferred to rural mothers and vice versa). Following the switch, cross-fostered mother-pup pairs were left in a small carrying bag for approximately a week for bonding, checked hourly to assess that the pup was being fed and cared for by its adoptive mother. Following this bonding period, cross-fostered pairs were placed back in their respective (urban/rural) colony based on the origin of the adoptive mother. Cross-fostering was carried out at a very young age, when pups were non-volant and completely dependent on their mothers for survival ( $45 \pm$ $4 \mathrm{~mm}$ forearm on average, equivalent to an age of 10 days at most). These pups were tested in their first foraging box-experiments on day $106 \pm 16$ on average, thus allowing ample time for maternal effects to take place.

\section{Behavioral analysis}

Video recordings of each session were independently watched and scored by 2 observers, to account for human error. A max of $5 \%$ of scoring events were in disagreements between the observers and were resolved by a third observer, who re-examined the disagreement and ruled. Scoring included annotating landings and entering of the boxes including the time and duration of each event, and the box number. This scoring was used to assess the following personality traits.

Risk-taking/boldness the box entry-to-landing ratio, that is the proportion of landing events that ended in box entries was used as a proxy of boldness. This measure was previously found to be strongly associated with a vigilant head-up posture accompanied by substantial ear movements that are typical for scanning the environment for potential threats or dangers in this species.

Exploration The proportion of boxes visited at least once was used as an estimate of exploration. Note that each box contained enough food for the entire night, so there was no need to test more bats.

Learning To assess how individuals learn to adapt to the changes, we assessed the average number of times a bat re-sampled a foraging box after experiencing that food was not accessible there. In this experiment only one box was accessible, the location of the open box was kept constant across all experiments.

\section{Milk cortisol}

Milk samples were collected from 31 wild caught lactating bats originating from urban and rural colonies $(n=$ 17, urban colony: Herzliya, $n=14$, rural colony: Beit Guvrin; respectively, Additional file 1: Table S1). Samples were collected $2 \mathrm{~h}$ post-capture, providing sufficient time for negative feedback to both kick in and ramp down cortisol secretion [66-68]. Furthermore, full mammary 
evacuation occurred within 2-5 min, meaning another acute release of cortisol may have not yet kicked in [67, 69]. We thus argue that the cortisol levels evaluated, represent the return to a post-recovery (close to baseline,). Collection was carried out separately from each mammary by gentle hand stripping of the nipple. To minimize sampling bias, each mammary was fully evacuated as indicated by the transition from streaming milk to solitary droplets of milk during hand collection. Full mammary evacuation occurred within 2-5 min for all subjects.

For consistency, all samples were collected, by a single researcher $2 \mathrm{~h}$ post capture. The samples were stored frozen at $-20{ }^{\circ} \mathrm{C}$ until milk composition analysis. Following milk collection mother-infant pairs were returned to their respective colonies.

To extract cortisol from bat milk, we used solid-phase extraction (SPE) with C18 columns, which has been shown to yield a high and consistent steroid recovery by removing potentially interfering lipids in a variety of tissue types $[70,71]$. Briefly, $50 \mu \mathrm{l}$ of milk was incubated in $500 \mu \mathrm{l}$ of ice-cold $80 \%$ HPLC-grade methanol $(\mathrm{MeOH})$ overnight at $4{ }^{\circ} \mathrm{C}$. Samples were then centrifuged (3000g for $10 \mathrm{~min}$ ) and supernatant was collected and added to $5 \mathrm{~mL}$ of deionized water, prior to loading on carbonbonded silica C18 filter column cartridges (Agilent Technologies, Santa Clara, USA) on a vacuum manifold. Columns were first primed with $5 \mathrm{ml}$ of $100 \%$ ethanol, equilibrated with $10 \mathrm{ml}$ deionized water before loading the diluted $5 \mathrm{~mL}$ sample. Next, $10 \mathrm{ml}$ of $40 \% \mathrm{MeOH}$ was used to remove lipids (e.g., triglycerides, cholesterols, and fatty acids) that could interfere with the cortisol assay [72]. Cortisol was then eluted using $5 \mathrm{ml}$ of $90 \%$ $\mathrm{MeOH}$ and these samples were dried in a speed vacuum concentrator (Thermo Fisher Scientific Inc, Pittsburgh, USA) at $60^{\circ} \mathrm{C}$ for $4 \mathrm{~h}$. All SPE extractions included a solvent blank as a negative control. Dried extracts were stored at $-20{ }^{\circ} \mathrm{C}$ until assayed for cortisol.

Cortisol concentration was quantified using an enzymelinked immunosorbent assay (ELISA) kit (Arbor Assays Inc, Ann Arbor, USA). Pooled milk samples were used to validate parallelism of a serial dilution with the assay standard curve, test the recovery of exogenous cortisol, and assess the removal of endogenous cortisol using dextran-coated charcoal (Additional file 1: Figure S3). All samples and standards were run in duplicate. Assay sensitivity was $24.1 \mathrm{pg} /$ $\mathrm{ml}$, and the intraassay coefficient of variation was 7.4\% $(n=$ 31 samples). Note that cortisol measurements likely represent maternal circulating levels, as mammary glands are not thought to synthesis it directly [73].

\section{Statistical analysis}

Mixed effect GLMs were used to compare urban and rural behavioral traits from all trials using MATLAB (R2018a, MathWorks Inc.). For every behavioral parameter examined (i.e., risk-taking, exploration, and learning), the origin (urban vs. rural), fostering condition (biological vs. adoptive mother), and their interaction was set as fixed effects while the bat's ID and the year of the experiment were set as random effects. When examining the effect of pup age and sex on behavior, these variables were added as another fixed effect $(n=86)$. We used the logit link function because we tested proportions.

To examine whether cross-fostered pups resembled their biological or adoptive mothers, we carried out Pearson's correlation tests between the average risktaking and exploration indices across repetitions of cross-fostered pups with their biological and adoptive mothers ( $n=11, n=7$; respectively). Initially, there were 11 biological mothers of cross-fostered pups; however, 2 pups died in their first week of life and were replaced with orphaned pups from the same origin (so the number of pups did not change, but we could not test their biological mother). An additional mother escaped before testing and the remaining mother was removed from the experiment due to health issues.

To assess individual consistency in both risk-taking and exploration, we carried out Pearson's correlation tests between all three repeats of the basic set-up for both mothers and pups (pups: trial $n=48$, trial $2 n=48$, trial $3 n=18$; mothers: trials 1,2 , and $3, n=21$; Additional file 1: Table S1).

\section{Supplementary Information}

The online version contains supplementary material available at https://doi. org/10.1186/s12915-021-01131-z.

Additional file 1: Figure S1. Adult urban bats are more prone to risktaking than rural bats. Figure S2. Pups are temporally consistent in their risk-taking and exploratory tendencies. Figure S3. Assay validations for the measurement of cortisol in Egyptian fruit bat milk. Table S1. Egyptian Fruit bat pups that were captured together with their mothers in natural rural and urban colonies between September-October 2017, AprilMay 2018, and April-May 2019. Each bat was brought to Zoological Garden in Tel Aviv University with their respective mothers.

\section{Acknowledgements}

We thank Reut Assa and all our undergraduate research assistants for their dedicated help in data collection and Lee Koren for Scientific consultancy.

Authors' contributions

L.H and Y.Y. designed the experiments and wrote the manuscript; N.G. M.H \& L.H conducted the experiment, data collection, and processing; L.H carried out the data analysis; O.D. carried out and analyzed the preliminary experiment; B.H.F Carried out milk cortisol analysis; Y.Y. supervised the study. All authors read and approved the final manuscript.

Funding

This study was partially supported by a research grant to Y.Y. from the EuropeanResearch Council (ERC-GPSBAT) and the Israeli Science Foundation grant number: 677/ 17. 


\section{Availability of data and materials}

The datasets supporting the conclusions of this article are available in the drobox repository: https://www.dropbox.com/sh/n8kyf3illrk7zzs/ AAAlogOJgEikXPVeCAta1Wiua?dl=0 [74]

\section{Declarations}

\section{Consent for publication}

Not applicable.

\section{Competing interests}

The authors declare that they have no competing interests.

\section{Author details}

${ }^{1}$ School of Zoology, Faculty of Life Sciences, Tel Aviv University, 69978 Tel Aviv, Israel. '2Department of Biology, Rollins College, P.O. Box 874601, Winter Park, Florida 32708, USA. ${ }^{3}$ Sagol School of Neuroscience, Tel Aviv University, 69978 Tel Aviv, Israel. ${ }^{4}$ Wissenschaftskolleg zu Berlin, Berlin, Germany.

Received: 30 December 2020 Accepted: 20 August 2021

Published online: 07 September 2021

\section{References}

1. Dingemanse NJ, Kazem AJN, Réale D, Wright J. Behavioural reaction norms: animal personality meets individual plasticity. Trends Ecol Evol. 2010;25(2): 81-9. https://doi.org/10.1016/J.TREE.2009.07.013.

2. Réale D, Reader SM, Sol D, McDougall PT, Dingemanse NJ. Integrating animal temperament within ecology and evolution. Biol Rev. 2007;82(2): 291-318. https://doi.org/10.1111/j.1469-185X.2007.00010.x.

3. Rangel-Patiño C, García-Morales C, Mastachi-Loza C, Carmen-Cristóbal JM, Ruiz-Gómez MDL. Personality and its variation between sexes in the blackbellied bunchgrass lizard Sceloporus aeneus during the breeding season. Ethology. 2018;124(11):796-803. https://doi.org/10.1111/ETH.12814.

4. Mazza V, Jacob J, Dammhahn M, Zaccaroni M, Eccard JA. Individual variation in cognitive style reflects foraging and anti-predator strategies in a small mammal. Sci Rep. 2019;9(1):1-9. https://doi.org/10.1038/s41598-019-46582-1.

5. Sih A, Bell A, Johnson JC. Behavioral syndromes: an ecological and evolutionary overview. Trends Ecol Evol. 2004;19(7):372-8. https://doi.org/1 0.1016/j.tree.2004.04.009

6. Wilson DS. Adaptive individual differences within single populations. Philos Trans R Soc London Ser B Biol Sci. 1998;353(1366):199-205. https://doi.org/1 0.1098/rstb.1998.0202.

7. Wolf M, van Doorn GS, Leimar O, Weissing FJ. Life-history trade-offs favour the evolution of animal personalities. Nature. 2007;447(7144):581-4. https:// doi.org/10.1038/nature05835.

8. Niemelä PT, Vainikka A, Hedrick AV, Kortet R. Integrating behaviour with life history: boldness of the field cricket, Gryllus integer, during ontogeny. Funct Ecol. 2012;26(2):450-6. https://doi.org/10.1111/j.1365-2435.2011.01939.x.

9. Aplin LM, Farine DR, Morand-Ferron J, Cole EF, Cockburn A, Sheldon BC. Individual personalities predict social behaviour in wild networks of great tits ( Parus major). Ecol Lett. 2013;16(11):1365-72. https://doi.org/10.1111/ ele.12181.

10. Dall SRX. Behavioural biology: fortune favours bold and shy personalities. Curr Biol. 2004;14(12):R470-2. https://doi.org/10.1016/j.cub.2004.06.011.

11. Massen JJM, Koski SE. Chimps of a feather sit together: chimpanzee friendships are based on homophily in personality. Evol Hum Behav. 2014; 35(1):1-8. https://doi.org/10.1016/J.EVOLHUMBEHAV.2013.08.008.

12. Cote J, Dreiss A, Clobert J. Social personality trait and fitness. Proc Biol Sci. 2008;275(1653):2851-8. https://doi.org/10.1098/rspb.2008.0783.

13. Richter SH, Hintze S. From the individual to the population - and back again? Emphasising the role of the individual in animal welfare science. Appl Anim Behav Sci. 2018;212:1-8. https://doi.org/10.1016/J.APPLANIM.201 8.12.012.

14. Drent PJ, van Noordwijk AJ, van Oers K, de Jong G, Kempenaers B. Contribution of genetics to the study of animal personalities: a review of case studies. Behaviour. 2005;142(9-10):1185-206. https://doi.org/10.1163/1 56853905774539364

15. Dall SRX, Griffith SC. An empiricist guide to animal personality variation in ecology and evolution. Front Ecol Evol. 2014;2:3. https://doi.org/10.3389/ fevo.2014.00003
16. Dingemanse NJ, Wolf M. Recent models for adaptive personality differences: a review. Philos Trans R Soc B Biol Sci. 2010;365(1560):3947-58. https://doi. org/10.1098/rstb.2010.0221.

17. Schuett W, Tregenza T, Dall SRX. Sexual selection and animal personality. Biol Rev. 2010;85(2):217-46. https://doi.org/10.1111/j.1469-185X.2009.00101.x.

18. Wolf M, Weissing FJ. An explanatory framework for adaptive personality differences. Philos Trans R Soc B Biol Sci. 2010;365(1560):3959-68. https:// doi.org/10.1098/rstb.2010.0215.

19. Sih A, Cote J, Evans M, Fogarty S, Pruitt J. Ecological implications of behavioural syndromes. Ecol Lett. 2012;15(3):278-89. https://doi.org/10.1111/ j.1461-0248.2011.01731.x.

20. Wolf $M$, Weissing FJ. Animal personalities: consequences for ecology and evolution. Trends Ecol Evol. 2012;27(8):452-61. https://doi.org/10.1016/J. TREE.2012.05.001.

21. Sol D, Lapiedra O, González-Lagos C. Behavioural adjustments for a life in the city. Anim Behav. 2013;85(5):1101-12. https://doi.org/10.1016/J.ANBEHA V.2013.01.023.

22. Wright TF, Eberhard JR, Hobson EA, Avery ML, Russello MA. Behavioral flexibility and species invasions: the adaptive flexibility hypothesis. Ethol Ecol Evol. 2010;22(4):393-404. https://doi.org/10.1080/03949370.2010.505580.

23. Sol D, Timmermans S, Lefebvre L. Behavioural flexibility and invasion success in birds. Anim Behav. 2002;63(3):495-502. https://doi.org/10.1006/a nbe.2001.1953.

24. Lowry H, Lill A, Wong BBM. Behavioural responses of wildlife to urban environments. Biol Rev. 2013;88(3):537-49. https://doi.org/10.1111/brv.12012.

25. Jarjour C, Evans JC, Routh M, Morand-Ferron J. Does city life reduce neophobia? A study on wild black-capped chickadees. Behav Ecol. 2019;31: 123-31. https://doi.org/10.1093/beheco/arz167.

26. Fehlmann G, O'Riain MJ, Kerr-Smith C, Hailes S, Luckman A, Shepard ELC, et al. Extreme behavioural shifts by baboons exploiting risky, resource-rich, human-modified environments. Sci Rep. 2017;7(1):15057. https://doi.org/10.1 038/s41598-017-14871-2.

27. Baxter-Gilbert J, Riley JL, Whiting MJ. Bold New World: urbanization promotes an innate behavioral trait in a lizard. Behav Ecol Sociobiol. 2019; 73(8):105. https://doi.org/10.1007/s00265-019-2713-9.

28. Wat KKY, Herath APHM, Rus Al, Banks PB, Mcarthur C. Space use by animals on the urban fringe: interactive effects of sex and personality. Behav Ecol. 2020:31(2):330-9. https://doi.org/10.1093/beheco/arz194.

29. Schuett W, Dall SRX, Wilson AJ, Royle NJ. Environmental transmission of a personality trait: foster parent exploration behaviour predicts offspring exploration behaviour in zebra finches. Biol Lett. 2013;9(4):20130120. https:// doi.org/10.1098/rsbl.2013.0120.

30. Schuett W, Delfs B, Haller R, Kruber S, Roolfs S, Timm D, et al. Ground beetles in city forests: Does urbanization predict a personality trait? PeerJ. 2018;2018:e4360. https://doi.org/10.7717/peerj.4360.

31. Esch T, Heldens W, Hirner A, Keil M, Marconcini M, Roth A, et al. Breaking new ground in mapping human settlements from space - The Global Urban Footprint. ISPRS J Photogramm Remote Sens. 2017;134:30-42. https://doi.org/10.1016/J.ISPRSJPRS.2017.10.012.

32. Charmantier A, Demeyrier V, Lambrechts M, Perret S, Grégoire A. Urbanization Is Associated with Divergence in Pace-of-Life in Great Tits. Front Ecol Evol. 2017;5:53. https://doi.org/10.3389/fevo.2017.00053.

33. Sprau P, Dingemanse NJ. An Approach to Distinguish between Plasticity and Non-random Distributions of Behavioral Types Along Urban Gradients in a Wild Passerine Bird. Front Ecol Evol. 2017:5:92. https://doi.org/10.3389/ fevo.2017.00092.

34. Evans J, Boudreau K, Hyman J. Behavioural Syndromes in Urban and Rural Populations of Song Sparrows. Ethology. 2010;116:588-95. https://doi.org/1 0.1111/j.1439-0310.2010.01771.x.

35. Lowry H, Lill A, Wong BBM. Tolerance of Auditory Disturbance by an Avian Urban Adapter, the Noisy Miner. Ethology. 2011;117(6):490-7. https://doi. org/10.1111/j.1439-0310.2011.01902.x.

36. Lapiedra O, Chejanovski Z, Kolbe JJ. Urbanization and biological invasion shape animal personalities. Glob Chang Biol. 2017;23(2):592-603. https://doi. org/10.1111/gcb.13395.

37. Møller AP. Flight distance of urban birds, predation, and selection for urban life. Behav Ecol Sociobiol. 2008;63(1):63-75. https://doi.org/10.1007/s00265008-0636-y.

38. Audet J-N, Ducatez S, Lefebvre L. The town bird and the country bird: problem solving and immunocompetence vary with urbanization. Behav Ecol. 2016;27(2):637-44. https://doi.org/10.1093/beheco/arv201. 
39. Alberti M, Marzluff J, Hunt VM. Urban driven phenotypic changes: empirical observations and theoretical implications for eco-evolutionary feedback. Philos Trans R Soc B Biol Sci. 2017;372(1712):20160029. https://doi.org/10.1 098/rstb.2016.0029.

40. Stirling DG, Réale D, Roff DA. Selection, structure and the heritability of behaviour. J Evol Biol. 2002;15(2):277-89. https://doi.org/10.1046/j.1420-91 01.2002.00389.x.

41. Dingemanse NJ, Both C, Drent PJ, van Oers K, van Noordwijk AJ. Repeatability and heritability of exploratory behaviour in great tits from the wild. Anim Behav. 2002;64(6):929-38. https://doi.org/10.1006/anbe.2002.2 006.

42. Bize $P$, Diaz C, Lindström J. Experimental evidence that adult antipredator behaviour is heritable and not influenced by behavioural copying in a wild bird. Proc Biol Sci. 2012;279(1732):1380-8. https://doi.org/10.1098/rspb.2 011.1789.

43. Dochtermann NA, Schwab T, Sih A. The contribution of additive genetic variation to personality variation: heritability of personality. Proc R Soc B Biol Sci. 2015;282(1798):20142201. https://doi.org/10.1098/rspb.2014.2201.

44. Reddon AR. Parental effects on animal personality. Behav Ecol. 2012;23(2): 242-5. https://doi.org/10.1093/beheco/arr210.

45. Francis D, Diorio J, Liu D, Meaney MJ. Nongenomic transmission across generations of maternal behavior and stress responses in the rat. Science. 1999;286(5442):1155-8. https://doi.org/10.1126/science.286.5442.1155.

46. Hinde K, Skibiel AL, Foster AB, Del Rosso L, Mendoza SP, Capitanio JP. Cortisol in mother's milk across lactation reflects maternal life history and predicts infant temperament. Behav Ecol. 2015;26(1):269-81. https://doi. org/10.1093/beheco/aru186.

47. Stamps J, Groothuis TGG. The development of animal personality: relevance, concepts and perspectives. Biol Rev. 2010;85(2):301-25. https://doi.org/1 0.1111/j.1469-185X.2009.00103.x.

48. Curley JP, Mashoodh R, Champagne FA. Epigenetics and the origins of paternal effects. Hormones Behav. 2011;59(3):306-14. https://doi.org/10.101 6/j.yhbeh.2010.06.018.

49. Bagot RC, Meaney MJ. Epigenetics and the biological basis of gene $\times$ environment interactions. J Am Acad Child Adolesc Psychiatry. 2010;49(8): 752-71. https://doi.org/10.1016/j.jaac.2010.06.001

50. Harten L, Matalon Y, Galli N, Navon H, Dor R, Yovel Y. Persistent producerscrounger relationships in bats. Sci Adv. 2018:4(2):e1603293. https://doi. org/10.1126/sciadv.1603293.

51. Egert-Berg K, Handel M, Goldshtein A, Eitan O, Borissov I, Yovel Y. Fruit bats adjust their foraging strategies to urban environments to diversify their diet; 2021.

52. Wong BBM, Candolin U. Behavioral responses to changing environments. Behav Ecol. 2015:26(3):665-73. https://doi.org/10.1093/beheco/aru183.

53. Verbeek MEM, Drent PJ, Wiepkema PR. Consistent individual differences in early exploratory behaviour of male great tits. Anim Behav. 1994;48(5):111321. https://doi.org/10.1006/anbe.1994.1344.

54. Eising CM, Müller W, Groothuis TG. Avian mothers create different phenotypes by hormone deposition in their eggs. Biol Lett. 2006;2(1):20-2. https://doi.org/10.1098/rsbl.2005.0391

55. Groothuis TGG, Müller W, Von Engelhardt N, Carere C, Eising C. Maternal hormones as a tool to adjust offspring phenotype in avian species. Neurosci Biobehav Rev. 2005;29(22):329-52.

56. Ruuskanen S, Laaksonen T. Yolk hormones have sex-specific long-term effects on behavior in the pied flycatcher (Ficedula hypoleuca). Horm Behav. 2010;57(2):119-27. https://doi.org/10.1016/j.yhbeh.2009.09.017.

57. Lewanzik D, Kelm DH, Greiner S, Dehnhard M, Voigt CC. Ecological correlates of cortisol levels in two bat species with contrasting feeding habits. Gen Comp Endocrinol. 2012;177(1):104-12. https://doi.org/10.1016/j. ygcen.2012.02.021.

58. Reeder DM, Kosteczko NS, Kunz TH, Widmaier EP. Changes in baseline and stress-induced glucocorticoid levels during the active period in free-ranging male and female little brown myotis, Myotis lucifugus (Chiroptera: Vespertilionidae). Gen Comp Endocrinol. 2004;136(2):260-9. https://doi.org/1 0.1016/J.YGCEN.2003.12.020.

59. Reeder DM, Kunz TH, Widmaier EP. Baseline and stress-induced glucocorticoids during reproduction in the variable flying fox, Pteropus hypomelanus (Chiroptera: Pteropodidae). J Exp Zool A Comp Exp Biol. 2004; 301(8):682-90. https://doi.org/10.1002/JEZ.A.58.

60. Wellnitz O, Bruckmaier RM. Invited review: The role of the blood-milk barrier and its manipulation for the efficacy of the mammary immune response and milk production. J Dairy Sci. 2021;104(6):6376-88. https://doi org/10.3168/JDS.2020-20029.

61. Brown J. The theory of insular biogeography and the distribution of boreal birds and mammals. Gt Basin Nat Mem. 1978;2 https://scholarsarchive.byu. edu/gbnm/vol2/iss1/14. Accessed 24 Aug 2020.

62. Wiens JJ, Donoghue MJ. Historical biogeography, ecology and species richness. Trends Ecol Evol. 2004;19(12):639-44. https://doi.org/10.1016/j. tree.2004.09.011.

63. Lyons J, Mastromonaco G, Edwards DB, Schulte-Hostedde Al. Fat and happy in the city: Eastern chipmunks in urban environments. Behav Ecol. 2017; 28(6):1464-71. https://doi.org/10.1093/beheco/arx109.

64. Goldstein A, Harten L, Yovel Y. Mother bats facilitate pups' navigational learning. Curr Biol. 2021.

65. Kulzer E. Untersuchungen über die biologie von flughunden der gattung Rousettus Gray. Zeitschrift Morphol Ökologie Tiere. 1958;47(4):374-402. https://doi.org/10.1007/BF00407474

66. Nicolson NA. Measurement of cortisol. Handb Physiol Res Methods Heal Psychol. 2008:37-74. https://doi.org/10.4135/9781412976244.N3.

67. Romero LM, Reed JM. Collecting baseline corticosterone samples in the field: is under 3 min good enough? Comp Biochem Physiol Part A Mol Integr Physiol. 2005;140(1):73-9. https://doi.org/10.1016/j.cbpb.2004.11.004

68. Sapolsky RM, Romero LM, Munck AU. How Do Glucocorticoids Influence Stress Responses? Integrating Permissive, Suppressive, Stimulatory, and Preparative Actions. Endocr Rev. 2000;21(1):55-89. https://doi.org/10.1210/ EDRV.21.1.0389.

69. Lawrence MJ, Jain-Schlaepfer S, Zolderdo AJ, Algera DA, Gilmour KM, Gallagher AJ, Cooke SJ. Are 3 minutes good enough for obtaining baseline physiological samples from teleost fish?. Can J Zool. 2018;96(7):774-86.

70. Fokidis HB, Prior NH, Soma KK. Fasting Increases Aggression and Differentially Modulates Local And Systemic Steroid Levels in Male Zebra Finches. Endocrinology. 2013;154(11):4328-39. https://doi.org/10.1210/en.2 013-1171.

71. Mack Z, Fokidis HB. A novel method for assessing chronic cortisol concentrations in dogs using the nail as a source. Domest Anim Endocrinol. 2017:59:53-7. https://doi.org/10.1016/j.domaniend.2016.11.003.

72. Newman AEM, Chin EH, Schmidt KL, Bond L, Wynne-Edwards KE, Soma KK. Analysis of steroids in songbird plasma and brain by coupling solid phase extraction to radioimmunoassay. Gen Comp Endocrinol. 2008;155(3):503-10. https://doi.org/10.1016/j.ygcen.2007.08.007.

73. Hamosh M. Bioactive factors in human milk. Pediatr Clin North Am. 2001; 48(1):69-86. https://doi.org/10.1016/S0031-3955(05)70286-8.

74. Harten L, Gonceer N, Handel M, Orit D, Fokidis HB, Yovel Y. Urban/rural personality and milk analysis Dropbox Data; 2021.

\section{Publisher's Note}

Springer Nature remains neutral with regard to jurisdictional claims in published maps and institutional affiliations.

Ready to submit your research? Choose BMC and benefit from

- fast, convenient online submission

- thorough peer review by experienced researchers in your field

- rapid publication on acceptance

- support for research data, including large and complex data types

- gold Open Access which fosters wider collaboration and increased citations

- maximum visibility for your research: over $100 \mathrm{M}$ website views per year

At $\mathrm{BMC}$, research is always in progress.

Learn more biomedcentral.com/submission 